\title{
Environmental Enrichment and Postnatal Handling Prevent Spatial Learning Deficits in Aged Hypoemotional (Roman High-avoidance) and Hyperemotional (Roman Low-avoidance) Rats
}

Rosa Maria Escorihuela, Adolf Tobeña, and Albert Fernández-Teruel

Medical Psychology Unit

Department of Pharmacology and Psychiatry

School of Medicine

Autonomous University of Barcelona

08193-Bellaterra, Barcelona, Spain

\section{Abstract}

The present study investigated the enduring effects of postnatal handling (administered during the first 21 days of life), and environmental enrichment (for a period of 6 months starting 3 weeks after weaning) on spatial learning in 24-month-old hypoemotional (Roman high-avoidance, RHA/Verh) and hyperemotional (Roman low-avoidance, RLA/Verh) rats. Two groups of 5-month-old rats from both lines were also included in the experiment as young controls. The Roman lines performed differently in the Morris water maze: Path lengths of RLA/Verh rats were shorter and they swam at lower speed than RHA/Verh rats, showing quicker and more efficient learning overall. Postnatal handling improved learning mainly in RHA/Verh rats, whereas environmental enrichment was able to prevent the deficits shown by aged controls of both lines. Young, enriched, and handled plus enriched animals exhibited better performance than impaired aged controls, to the point that aged enriched and handled plus enriched animals did not differ from young controls. Thus, besides indicating that RLA/Verh rats are better learners than RHA/Verh rats in the Morris water maze, this study demonstrates that environmental enrichment prevents the cognitive loss associated with aging, over the long term. Finally, the positive effects obtained with postnatal handling were dependent on the rat line.

\section{Introduction}

Early exposure of animals to enriched environment leads to an enhancement of brain growth and increases in the density of neurons and synaptic contacts, as well as the size of neuronal nuclei and the number of dendritic branches (Diamond 1988; Greenough et al. 1990). Several behavioral studies have also demonstrated that enriched rats are high explorers and good performers in several labyrinths and conflict tasks (Renner and Rosenzweig 1987; Escorihuela et al. 1994), two properties that might be related with the modifications induced by early enrichment in neuronal substrates underlying memory and learning (Paylor et al. 1992) or on neuroendocrine factors at the hippocampal level (Olsson et al. 1994). Nevertheless, there are only a few studies on the effects of environmental enrichment as a procedure for preventing the learning deficits associated with aging (Van Gool et al. 1985).

On the other hand, neonatal handling during the first 21 days of life has been shown to reduce emotional reactivity as measured by defecation, ambulation, or exploratory activity in novel situations (DeNelsky and Denenberg 1967; Levine et al. 1967), by eating measures in the hyponeophagia test (Ferré et al. 1995) and by the ability to cope

LEARNING \& MEMORY 2:40-48 @ 1995 by Cold Spring Harbor Laboratory Press ISSN1072-0502/95 \$5.00

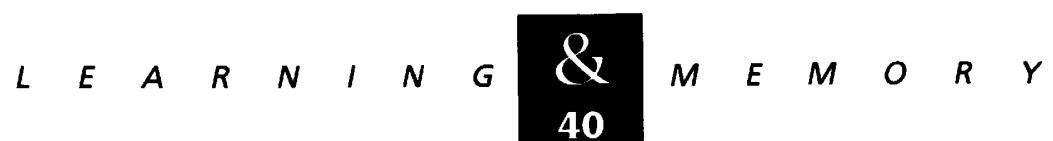


with aversive conflicts (Escorihuela et al. 1994; Núñez et al. 1995). Moreover, postnatal handling decreases corticosterone and adrenocorticotropin (ACTH) levels in response to a variety of stressors (Denenberg and Zarrow 1971; Levine et al. 1967), also inducing faster returns to basal levels following the termination of a stress (Meaney et al. 1988) and increases of hippocampal glucocorticoid receptors (Meaney et al. 1989). It has been hypothesized that postnatal handling could prevent the cognitive impairment and neuronal loss associated with aging, as a result of those alterations in the reactivity of the hypothalamo-pituitary-adrenal (HPA) axis (Meaney et al. 1988).

The main aim of the present study was to further investigate the long-term effects of environmental enrichment and/or postnatal handling treatments in two psychogenetically selected rat lines differing in emotional reactivity, as well as in learning and memory capabilities. Thus, the study was undertaken with the Roman high- and lowavoidance rat lines (RHA/Verh and RLA/Verh, respectively), which have been bred selectively for good (RHA/Verh) versus extremely poor (RLA/ Verh) shuttle box (two-way active) avoidance learning (Bignami 1965; Driscoll and Bättig 1982). The hyperemotional RLA/Verh rats compared with the hypoemotional RHA/Verh rats, present higher heart rates, plasma levels of corticosterone, $\mathrm{ACTH}$, and prolactin, as well as higher defecation and freezing responses to mildly stressful situations (Gentsch et al. 1982; Fernández-Teruel et al. 1992; see Driscoll and Bättig 1982). The Roman rat lines have also been proposed as a psychogenetic model for the study of working memory (Willig et al. 1991), because several studies have shown that the RLA line performs more efficiently than the RHA line in an exploratory maze and in the Hebb-Williams test (Nil and Bättig 1981), as well as in tests of working memory, such as delayed reinforced alternation, object recognition, and radial maze (see Willig et al. 1992) and in tasks of lever-pressing for food reward (Zeier et al. 1978).

Previous work conducted in our laboratory indicated that both postnatal handling and environmental enrichment decreased emotional reactivity and increased exploratory behavior in both lines at young and middle ages, although the degree of the obtained effects was dependent on the rat line (Fernández-Teruel et al. 1991, 1992). In the present study, young and old untreated RHA/ Verh and RLA/Verh rats, as well as 24-month-old postnatally handled and/or environmentally enriched rats from both lines, were tested in the Morris water maze. The purposes of the study were to determine (1) whether the Roman rat lines differed in a place-spatial learning task both at young and old ages, as expected from the abovementioned results; (2) whether the postnatal handling treatment, which has been shown to reduce both emotional reactivity and cognitive deficits associated with aging, as well as environmental enrichment, could improve spatial learning in aged RHA/Verh and RLA/Verh rats, and (3) whether the degree of the effects obtained were dependent on the rat line.

\section{Materials and Methods}

\section{ANIMALS}

A total of $32 \mathrm{RHA} /$ Verh and $40 \mathrm{RLA} /$ Verh male rats were used. They were maintained with free access to food and water in a temperature- and light-controlled room $\left(22 \pm 2^{\circ} \mathrm{C}, 12\right.$-hr light cycle starting at 8:30 a.m. ). The animals were kindly supplied by Dr. Peter Driscoll (ETH-Zentrum, Animal Sciences Institute, Zurich, Switzerland). The 24month-old subjects used in this study had been tested previously for emotional reactivity and exploratory behavior in the hexagonal tunnel maze at 30 days of age (Fernández-Teruel et al. 1991) and, in the open field and hole-board tests at 8 and 9 months of age, respectively (Fernández-Teruel et al. 1992).

\section{TREATMENTS AND EXPERIMENTAL GROUPS}

Animals receiving postnatal handling were placed individually in plastic cages twice daily (morning and evening) for $10 \mathrm{~min}$ from postnatal days 1 to 21, as described previously (FernándezTeruel et al. 1991). Unhandled animals were left undisturbed. For a total period of 6 months, 6-week-old animals receiving environmental enrichment were placed in groups of 10-12 in cages $(100 \times 43 \times 50 \mathrm{~cm})$ containing several objects and "playthings," which were changed every 2 days. Similarly, the internal configuration of the cages was changed every 2 days, creating different spaces with several types of stairs, ropes, tunnels, and so forth. Unenriched animals were housed in pairs in standard macrolon cages.

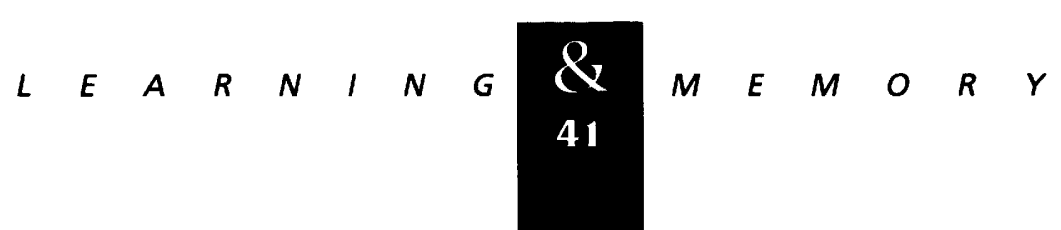


The subjects were tested for place spatial learning at the age of $\mathbf{2 4}$ months, with the experimental groups being the following: $\mathrm{RHA} / \mathrm{C}$ and RLA/C, aged rats of both lines receiving no treatment; RHA/H and RLA/H, animals that were postnatally handled; RHA/E and RLA/E, enriched animals; RHA/HE and RLA/HE, animals receiving both postnatal handling and environmental enrichment. Two additional groups of 5-month-old rats from both lines coming from different cohorts were also tested as young control groups (RHA/Y and RLA/ Y). There were animals from three to four different litters in each experimental group. (Table 1 shows the number of animals in each group.)

\section{WATER MAZE PROCEDURE}

Testing was performed over 9 days. Acquisition (days 1-5) and reversal (days 6-9) consisted of five and four, respectively, 4-trial sessions spaced $24 \mathrm{hr}$ apart. In each trial, rats were placed at one of the starting locations [north, south, east, west $(\mathrm{N}, \mathrm{S}, \mathrm{E}, \mathrm{W})$, including permutations of the four starting points per session] of a swimming pool ( $140 \mathrm{~cm}$ diam., $30 \mathrm{~cm}$ deep) filled with water $\left(24^{\circ} \mathrm{C}\right)$ made opaque with milk. The animals were allowed to swim until they located a platform (diam. $16 \mathrm{~cm}$; height $28 \mathrm{~cm}$ ) submerged in a fixed

Table 1: Swimming speeds (mean \pm S.E.) averaged over 5 days of acquisition and 4 days of reversal

\begin{tabular}{lccc}
\hline & $\begin{array}{c}\text { Animals } \\
\text { (no.) }^{\mathrm{a}}\end{array}$ & Acquisition & Reversal $^{-}$ \\
\hline RHA/Y & 6 & $22.9 \pm 1.1$ & $28.2 \pm 1.3$ \\
RHA/C & 7 & $19.5 \pm 0.7^{\mathrm{b}}$ & $22.3 \pm 1.1^{\mathrm{b}}$ \\
RHA/H & 7 & $19.4 \pm 0.7^{\mathrm{b}}$ & $22.8 \pm 0.8^{\mathrm{b}}$ \\
RHA/E & 6 & $19.4 \pm 0.6^{\mathrm{b}}$ & $22.7 \pm 1.3^{\mathrm{b}}$ \\
RHA/HE & 7 & $20.8 \pm 0.8$ & $23.7 \pm 1.2^{\mathrm{b}}$ \\
RLA/Y & 6 & $21.8 \pm 1.6$ & $25.1 \pm 1.3^{\mathrm{s}}$ \\
RLA/C & 7 & $16.7 \pm 0.7^{\mathrm{b}}$ & $17.9 \pm 1.0^{\mathrm{b}}$ \\
RLA/H & 10 & $18.6 \pm 0.8^{\mathrm{b}}$ & $19.1 \pm 0.5^{\mathrm{b}}$ \\
RLA/E & 7 & $19.8 \pm 1.1$ & $21.5 \pm 1.1^{\mathrm{b}, \mathrm{c}}$ \\
RLA/HE & 10 & $20.1 \pm 0.8^{\mathrm{c}}$ & $22.5 \pm 1.1^{\mathrm{c}}$ \\
\hline
\end{tabular}

(Y) young controls; $(C)$ aged controls; $(H)$ handled; $(E)$ enriched; (HE) handled plus enriched.

a Number of animals in each experimental group.

${ }^{\mathrm{b}} P<0.05$ vs. the corresponding RHA/Y or RLA/Y group.

${ }^{c} P<0.05$ vs. the corresponding RHA/C or RLA/C group

(Duncan's test). position (a SE quadrant in acquisition and a NW quadrant in reversal). Rats failing to find the platform within $120 \mathrm{sec}$, were placed on it for $30 \mathrm{sec}$ (the same period of time as the successful animals). Several room cues were constantly visible from the pool. At the end of every daily session the rats were allowed to dry for $10 \mathrm{~min}$ in a heated enclosure and returned to their home cage. Escape latencies, path lengths, and swimming speed from each rat and trial were provided by a tracking system (Smart, Letica Instruments) connected to a video camera placed above the pool.

Two probe tests consisting of removing the platform immediately after the last trial of acquisition (probe 1, day 5) and the last trial of reversal (probe 2, day 9) were performed. All rats were released from the $\mathrm{N}$ and $\mathrm{E}$ starting points in probe tests 1 and 2, respectively, and the time spent in each quadrant for a period of $60 \mathrm{sec}$ was recorded by the video-tracking system.

\section{STATISTICS}

A mean path-length score was obtained for each animal and session as the average of each of four consecutive trials, so that each rat has five values for acquisition (session 1-5) and four values for reversal (session 6-9). These path-length scores were square-root-transformed (to normalize data), before applying the analysis of variance with repeated measures (MANOVA). Swimming speed, averaged over the five sessions of acquisition and over the four sessions of reversal, was analyzed by ANOVA. Two analyses were performed: The first one included RHA/C, RHA/Y, $\mathrm{RLA} / \mathrm{C}$, and $\mathrm{RLA} / \mathrm{Y}$ groups for investigation of the differences between lines and between young and aged rats (MANOVA factors, line $\times$ age $\times$ session; ANOVA factors, line $\times$ age $)$. In the second analysis, $\mathrm{C}, \mathrm{H}, \mathrm{E}$, and $\mathrm{HE}$ groups of both lines were included, to evaluate the effects of the treatments and their interactions in aged rats (MANOVA factors, line $\times$ handling $\times$ enrichment $\times$ session; ANOVA factors, line $\times$ handling $\times$ enrichment). Posthoc comparisons between groups were performed by Duncan's multiple range tests.

The time spent in each of the four quadrants, expressed as a percentage of the duration of the probe trial, was analyzed by three-way (factors, line $\times$ age $\times$ quadrant) or four-way (line $\times$ handling $\times$ enrichment $\times$ quadrant) ANOVAs. For each group, comparisons between the time spent in each quadrant were performed by Duncan's tests.

$$
\text { n....... }
$$




\section{Results}

SWIMMING SPEED

Swimming speeds are presented in Table 1. The two-way ANOVA analyses (factors, line $\times$ age) indicated that aging reduced overall swimming speed in acquisition [age effect, $F(1,25)=16.1$, $P<0.001$ ] and reversal [age effect, $F(1,25)=33.8$, $P<0.001]$, although the percentage of reduction was greater in old RLA/Verh rats (acquisition, $23.4 \%$; reversal, $28.7 \%$ ) than in old RHA/Verh rats (acquisition, 14.9\%; reversal, 20.9\% ). RLA/Verh rats swam slower than RHA/Verh rats during acquisition (statistical tendency, $P=0.07$ ) and reversal trials [line effect, $F(1,25)=11.2, P<0.01$ ]

In aged rats, the three-way ANOVA (line $\times$ handling $\times$ enrichment) showed that enrichment treatment enhanced speed in acquisition (enrichment effect, $F(1,59)=6.44, P<0.05)$ and reversal $[F(1,59)=11.5, P<0.001]$, mainly in the RLA/Verh line [enrichment $\times$ line interaction, $F(1,59)=4.2$, $P<0.05]$. Postnatal handling did not affect swimming speed.

\section{LINE AND AGE EFFECTS}

Because the escape latencies could be contaminated by basal levels in swimming speed, path lengths from acquisition and reversal were used as the main measures of place spatial learning (Fig. $1 A, B$ ). The MANOVAs (age $\times$ line $\times$ session) with repeated measures (acquisition, sessions 1-5; reversal, sessions 6-9) indicated that path lengths performed by RLA/Verh rats were shorter than those from RHA/Verh rats both in acquisition and reversal [line effects, $F(1,22)=12.8, P<0.01$, and $F(1,22)=13.8, P<0.001$, respectively], indicating that RLA/Verh animals found the platform through more efficient paths. These analyses also revealed that young animals learned faster than aged animals, as overall significant age effects [acquisition, $F(1,22)=11.24, P<0.01 ;$ reversal, $F(1,22)=7.36$, $P<0.05$ ], and a significant "age $\times$ session" interaction [acquisition, $F(4,88)=2.50, P<0.05$ ] were also found.

In probe tests $1-2$ (in the absence of the platform), there were significant quadrant effects [three-way ANOVA, $F(3,101)=36,82, P=0.000$, and $F(3,101)=48,51, P=0.000$, respectively]. RLA/Verh rats spent more time in the training quadrant (SE and NW quadrants in probe tests 1 and 2, respectively) than RHA/Verh rats [line $\times$ quadrant interactions: $\quad F(3,101)=4.80$, $P<0.01$, and $F(3,101)=8.43, P<0.001$, in probe tests 1 and 2 , respectively]. A significant "age $\times$ quadrant" interaction, $[F(3,101)=2.74, P<0.05]$, appeared in the analysis of probe test 1 , thus indicating that aged rats spent less time in the training quadrant than young rats. RHA/Y, RLA/Y, and RLA/C groups spent more time in the training quadrant than in all of the other quadrants, both during probe test 1 and $2(P<0.05$ Duncan's test; Fig. 2), whereas the RHA/C group did not significantly discriminate the training quadrant from the other three.

\section{HANDLING AND ENRICHMENT EFFECTS IN 24-MQNTH-OLD RATS}

MANOVA with repeated measures (acquisition, sessions 1-5, reversal, sessions 6-9) and factors "line $\times$ handling $\times$ enrichment" indicated that both handling and enrichment decreased path lengths over acquisition [handling effect, $F(1,59)=4.45, \quad P<0.05 ; \quad$ enrichment effect, $F(1,59)=17.04, P<0.001]$, the latter treatment being almost significant across sessions [enrichment $\times$ session interaction, $F(4,208)=2.39$, $P=0.052]$. As in the previous analyses, the two lines showed different performance in acquisition, as both a significant line effect $[F(1,59)=23.05$, $P<0.001]$ and a "line $\times$ session" interaction $[F(4,208)=63.5, P<0.0001]$ were found, indicating that $\mathrm{RLA} /$ Verh rats reached the asymptotic level of efficient swimming earlier. Enriched and young control RHA/Verh animals already reached the asymptotic level of $360-460 \mathrm{~cm}$ by session 3 , whereas the respective aged control group never attained that performance level. In contrast, aged and handled RLA/Verh rats reached the asymptotic level of $300 \mathrm{~cm}$ by session 4 , whereas young controls and animals receiving both treatments (postnatally handled plus enriched group) attained that level by session 2 and still improved their performance over training, achieving path lengths of 100 and $240 \mathrm{~cm}$, respectively, by the end of the acquisition training (session 5, Fig. 1).

Concerning the reversal sessions, the MANOVA with repeated measures (days 6-9) also showed that environmental enrichment decreased path lengths $[F(1,59)=6.86, P<0.05]$. There was also an overall significant line effect $[F(1,59)=$ 13.09, $P<0.001]$, and a significant "line $\times$ handling $\times$ enrichment" interaction $[F(1,59)=$ $4.58, P<0.05$ ], probably as a result of a significant

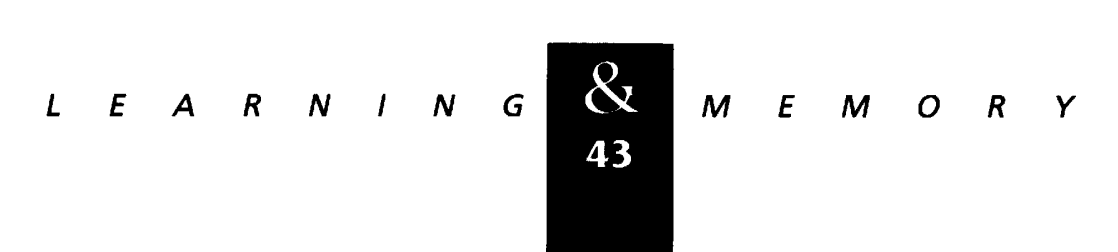




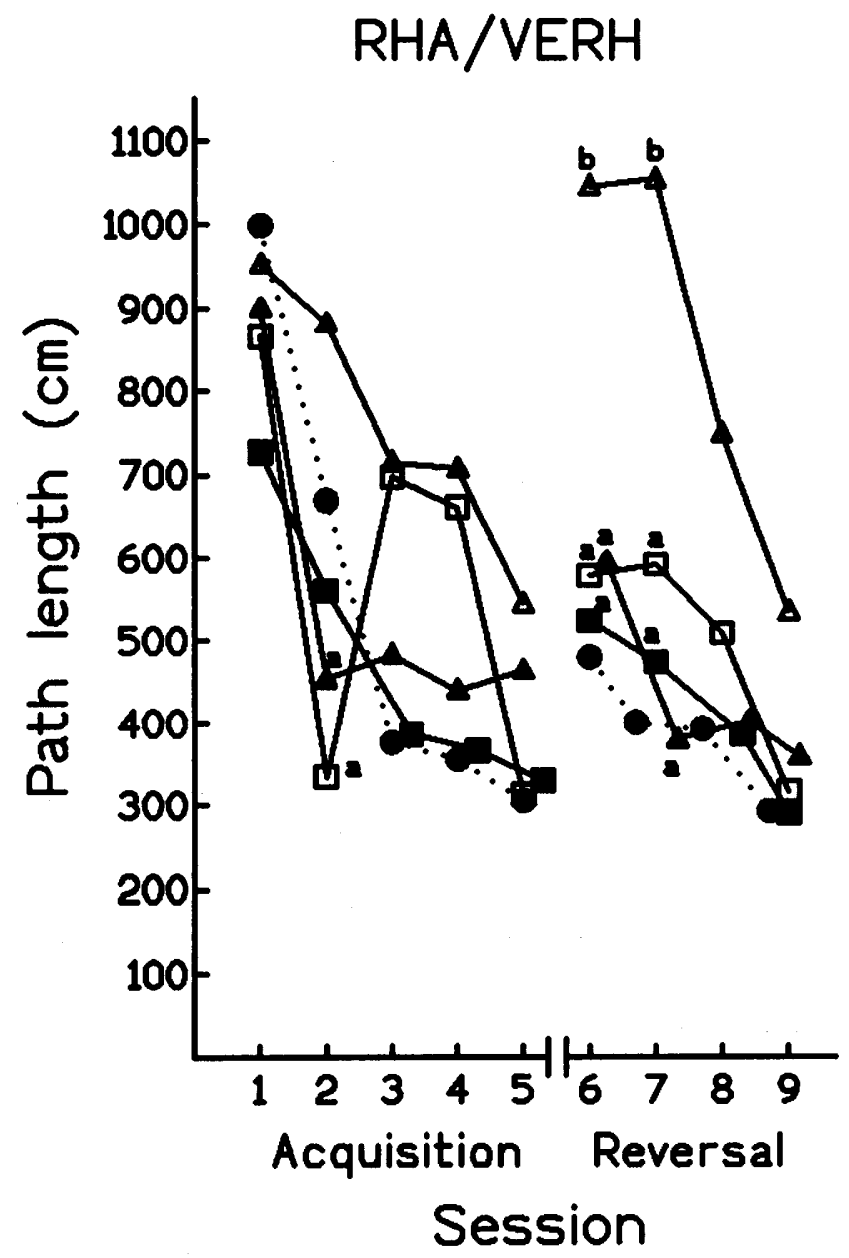

RLA/VERH

Figure 1: Performance shown by young controls $(\boldsymbol{O})$ and aged controls $(\triangle)$, handled $(\square)$, enriched $(\boldsymbol{\Delta})$, and handled plus enriched ( $\mathbf{0}$ ) 24-month-old RHA/Verh and RLA/Verh rats in the Morris water maze. Means of path length over acquisition (sessions 1-5) and reversal (sessions 6-9) are shown. (a) $P<0.05$ vs. the corresponding RHA/C or RLA/C group; (b) $P<0.05$ vs. the corresponding RHA/Y or RLA/Y group (Duncan's test).

improval in environmental treatment of the RHA/ Verh line.

Overall significant quadrant effects [probe 1, $F(3,237)=85.71, P<0.0001$, probe $2, F(3,327)=$ $69.80, P<0.0001]$ and significant "line $\times$ quadrant" interactions [probe $1, F(3,237)=3.057, P<0.05$; probe $2, F(3,237)=13.86, P<0.001]$ appeared in the ANOVA analyses (factors, line $\times$ handling $\times$ enrichment $\times$ quadrant), whereas these analyses did not show handling or enrichment overall effects on the time spent in each of the four quadrants.

Figure 2 shows that all the RLA/Verh groups spent more time in the training quadrant than in the rest of the pool, both during probe test 1 and $2(P<0.05$ between training and the remaining quadrants; Duncan's test). With respect to the RHA/Verh line, young and aged animals that had been given early treatments were able to discriminate between training and some of the other quadrants in probe test $1(P<0.05$, Duncan's test), whereas aged RHA/Verh controls did not discriminate between the four quadrants. In probe test 2 , only two of the four aged RHA/Verh groups, that is, RHA/H and RHA/E animals, discriminated between training and opposite quadrants.

\section{Discussion}

This study reports three main findings: (1) RLA/Verh rats are better learners in the Morris water maze than are RHA/Verh animals, with this difference persisting into senescence; (2) postnatal handling administered during the first 21 days of life has long-term beneficial effects mainly in

$$
\begin{array}{llllllllllllllll}
L & E & A & R & N & I & N & G & \& \\
44 & M & E & M & O & R & Y
\end{array}
$$



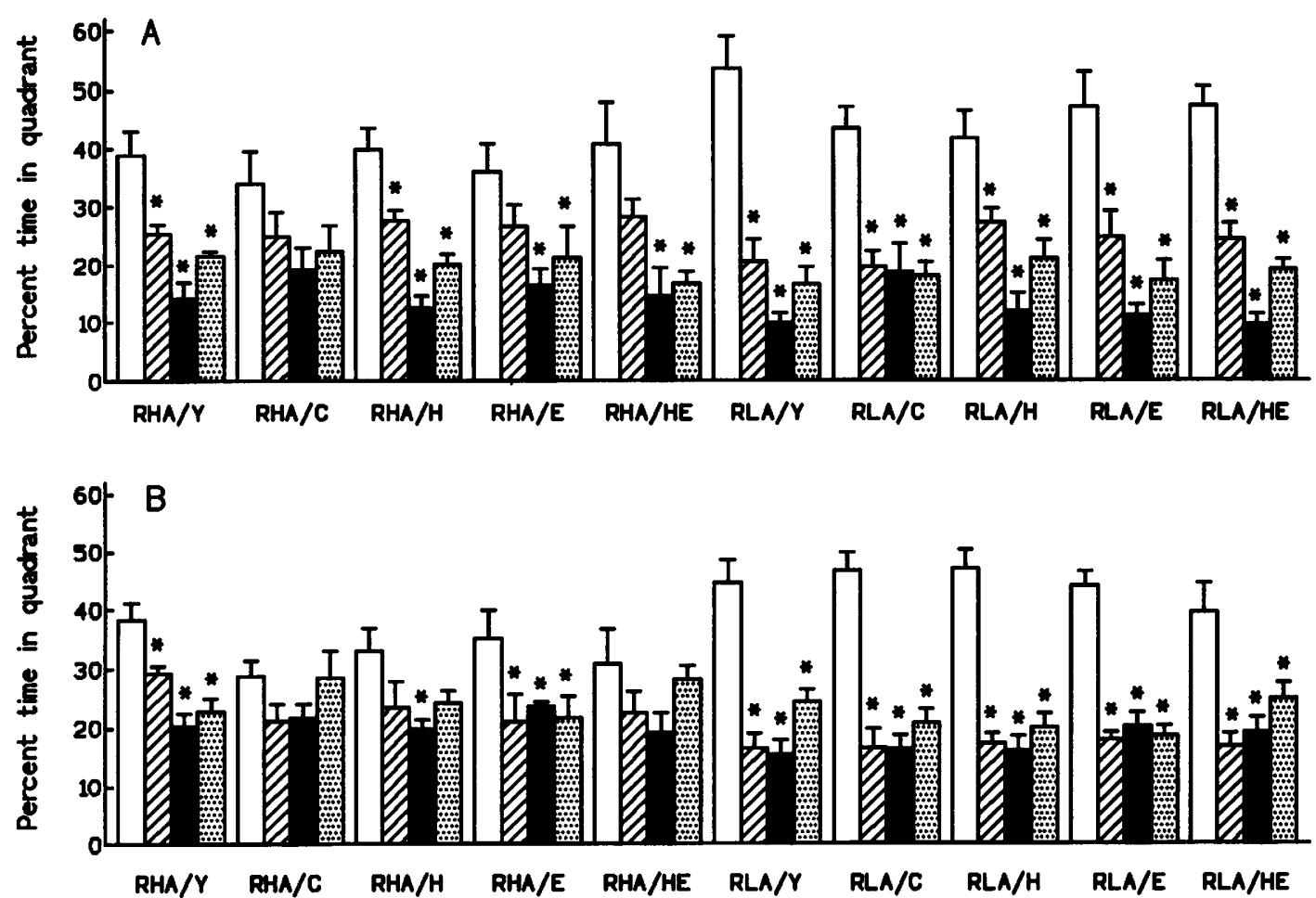

Figure 2: Percentage of time spent (mean \pm S.E.) in the training (open bars), adjacent right (hatched bars), opposite (solid bars), and adjacent left (dotted bars) quadrants by young controls $(\mathrm{Y})$ and aged controls $(\mathrm{C})$, handled $(\mathrm{H})$, enriched $(\mathrm{E})$, and handled plus enriched $(\mathrm{HE}) 24$-month-old RHA/Verh and RLA/Verh rats during probe test $1(A)$ and $2(B) .\left(^{*}\right) P<0.05$ vs. the training quadrant (same group, Duncan's test).

RHA/Verh rats; (3) environmental enrichment during adolescence and early adulthood prevents later age-associated learning deficits in both Roman rat lines.

The superiority of both young and old Roman low-avoidance rats (as compared with their respective RHA/Verh counterparts) in the Morris water maze is in keeping with other studies showing that RLA rats perform better than RHA rats in the Hebb-Williams test (except for problem 12; Nil and Bättig 1981), in the DRL-20 acquisition task for food reward (Zeier et al. 1978), and in three tests of working memory (spontaneous alternation, radial maze, and object recognition; Nil and Bättig 1981; Willig et al. 1992). Thus, RLA rats appear to be superior (genetically based) as compared with RHA rats in tasks where goal-directed behavior and efficient exploration are needed (Nil and Bättig 1981; Fernández-Teruel et al. 1993). Moreover, the present results might be consistent with the described differences in infra- and intrapyramidal mossy fiber projection (IIP-MF) morphology between RHA/Verh and RIA/Verh rats (Lipp et al. 1989). Thus, negative correlations between IIP-MFs morphology and two-way avoidance learning have been reported in mice and rats (Lipp et al. 1989), whereas positive correlations between IIP-MFs and swimming navigation have been found in mice (Lipp et al. 1989; Schöpke et al. 1991). Accordingly, because RLA/Verh rats have greater IIP-MF morphology and perform better in the water maze than RHA/Verh rats do, the present findings seem to be in agreement with previous studies dealing with relationships between hippocampal mossy fiber morphology and spatial learning ability.

Neuroendocrinological studies have shown increased HPA axis reactivity in the RLA/Verh line compared with the RHA/Verh line, as indicated by higher stress-induced ACTH and corticosterone release (Gentsch et al. 1982; Castanon et al. 1994), pituitary sensitivity to corticotropin-releasing factor (CRF) (Walker et al. 1989), and higher CRF and vasopressin (VP) mRNA levels in the paraventricular nucleus (Aubry et al. 1994). By analogy, it has been reported that stress-induced glucocorticoid hypersecretion leads to an increased hippocampal neuronal loss and, subsequently, to impor-

$$
\begin{array}{llllllllllllllll}
L & E & A & R & N & I & N & G & \begin{array}{l}
Q \\
45
\end{array} & M & E & M & O & R & Y
\end{array}
$$




\section{Escorihuela et al.}

tant spatial learning deficits in Long-Evans hooded rats (Issa et al. 1990). The superior performance of the hyperemotional RLA/Verh line observed here in the Morris water maze does not seem to be consistent with such findings. In contrast, it appears to be in keeping with a study from Yau et al. (1994) performed in Wistar rats (the parental strain of the Roman lines) indicating that aged poor spatial learning performers did not show alterations in neuroendocrine parameters when compared with unimpaired rats.

Meaney et al. (1988) and Sapolsky (1992) have demonstrated that postnatal handling treatment enduringly modifies HPA axis functioning by diminishing stress-induced glucocorticoid release and increasing hippocampal glucocorticoid receptors. These investigators have suggested that those neuroendocrine $\mathrm{H}$ effects could be responsible for the prevention of hippocampal neuronal loss and spatial learning deficits associated with aging (Meaney et al. 1988; Sapolsky et al. 1992). Previous behavioral studies performed in our laboratory with Roman rat lines showed that postnatal handling decreased emotional behavior in novel situations both in young and middle-aged rats (Fernández-Teruel et al. 1991, 1992) and moderately improved two-way active avoidance acquisition in RLA/Verh rats (Escorihuela et al. 1995). However, in this study, the long-term effects of postnatal handling were found mainly in RHA/ Verh rats, probably because the deficits shown by RHA/C rats were greater than those shown by RLA/C rats.

Thus, although $\mathrm{RHA} / \mathrm{H}$ rats apparently performed in some erratic way during acquisition, they discriminated perfectly the training quadrant in the two probe tests and they showed short path lengths during the reversal phase. In contrast, there were no statistical differences between the time spent in the four quadrants in old RHA controls during probe tests, and their path lengths during acquisition and reversal were longer than those of the young RHA controls. In the RLA/Verh line, the differences between young and old controls appeared mainly in acquisition (sessions 1-5). Because RLA/C rats spent almost $50 \%$ of their time in the training quadrant during probe tests 1 and 2, and as there were no significant differences between the RLA groups in the reversal phase, a possible floor effect in RLA/Verh rats cannot be ruled out at present. On the whole, the better performance of aged RLA controls as compared with aged RHA controls, as well as the greater effect of handling in the RHA line, is difficult to explain solely on the basis of differential HPA axis functioning (or reactivity to stress) between both rat lines. Altogether, a detailed analysis of neurohormonal measures in RLA/Verh and RHA/Verh rats receiving early treatment seems mandatory to understand changes related to learning and senescence.

The main finding of the present experiment was, however, the far-reaching improvement of place-spatial learning produced by environmental enrichment. Enriched animals (both enriched and handling plus enriched groups in each line) performed as efficiently as the young controls. They reached asymptotic swimming levels at a point similar to young animals. Previous reports have indicated that early exposure to an enriched environment resulted in better spatial performance when testing was carried out either immediately after treatment in animals of 3-4 months of age (Paylor et al. 1992) or some months later (Liljequist et al. 1993). These findings are in contrast with those showed by Van Gool et al. (1985), indicating no positive enrichment effects, either in young nor in old brown Norway rats, when tested in an 8-arm radial maze. Nevertheless, the fact that enviornmental enrichment lasted 7-8 weeks and was administered at the ages of $\sim 5-6$ and $28-31$ months (in young and old rats, respectively) could account for those discrepancies. On the other hand, positive effects of an early enriched environment have also been reported in a Hebb-Williams test administered 2 months after treatment (Venable et al. 1988) and after a delay of 10 months (Denenberg et al. 1968). Moreover, in the Roman rat lines, previous work showed that enrichment increased exploration and reduced emotionality 3 months after treatment (Fernández-Teruel et al. 1992). Thus, in addition to reporting long-term actions in the Roman lines, the present results strongly suggest that environmental enrichment probably promotes enduring neural modifications that can prevent age-related spatial learning deficits, although the mechanisms of these effects remain unclear (see Renner and Rosenzweig 1987; Greenough et al. 1990; Paylor et al. 1992; Olsson et al. 1994).

There are some aspects of the enrichment treatment that merit consideration. Because one of the principal aims of the study was to investigate the long-term effects of environmental enrichment at old age, the animals were exposed to the enrichment cages for a period of 6 months. Appar-

$$
\begin{array}{llllllllllllllll}
L & E & A & R & N & I & N & G & \begin{array}{l}
\ell \\
46
\end{array} & M & E & M & O & R & Y
\end{array}
$$


ently there was no habituation because the latency shown by the subjects in their interaction with changing objects and playthings decreased as the treatment progressed. They took about half an hour to approach the new objects at first, but interacted immediately and very actively during the last 2 months of enriched housing. The environmental changes (every 2 or 3 days) were made with rectangular pieces of steel for dividing temporarily the total space of the cage into two floors or into two compartments connected by an opening: by placing tunnels, stairs, ramps, and strings in a way that the animals could move and explore through different paths; by changing or even hiding the food container; and by moving toys of different shapes and materials that were left on the floor or hung from the walls or the roof.

Finally, it seems difficult to explain the overall better spatial performance shown by RLA rats and the improvements induced by the early treatments solely on the basis of emotional or motivational differences: Although the higher emotionality of RLA rats could have induced a more efficient escape from the pool, the two treatments enhanced maze performance despite their well-established and long-lasting action of decreasing emotionality in the Roman lines and other strains as well (Levine et al. 1967; Renner and Rosenzweig 1987; Meany et al. 1988; Fernández-Teruel et al. 1991, 1992). Accordingly, we conclude that this is the first report demonstrating permanent preventive effects of environmental enrichment on age-related spatial learning deficits in two rat lines that differ both in their basal emotionality levels and in their spatial learning ability.

\section{Acknowledgments}

This work (R.M.E.) received support from the Fondo de Investigaciones Sanitarias (FISSs, 92/0712). We thank Drs. J.F. Núnez and $P$. Ferré for their valuable help.

The publication costs of this article were defrayed in part by payment of page charges. This article must therefore be hereby marked "advertisement" in accordance with 18 USC section 1734 solely to indicate this fact.

\section{References}

Aubry, J.M., V. Bartanusz, P. Driscoll, P. Schulz, T. Steimer, and J.Z. Kiss. 1994. Corticotropin-releasing factor (CRF) and vasopressin (VP) mRNA levels in Roman high- and low-avoidance (RHA-RLA) rats; Response to open field exposure. Neuroendocrinology 61: 89-97.
Bignami, G. 1965. Selection for high rates and low rates of avoidance conditioning in the rat. Animal Behav. 13: $221-227$.

Castanon, N., J. Dulluc, M. Le Moal, and P. Mormede. 1994. Maturation of the behavioral and neuroendocrine differences between the Roman rat lines. Physiol. Behav. 55: 775-782.

DeNelsky, G.Y. and V.H. Denenberg. 1967. Infantile stimulation and adult exploratory behavior: Effects of handling upon tactual variation seeking. J. Comp. Physiol. Psychol. 63: 309-312.

Denenberg, V.H. and M.X. Zarrow. 1971. Effects of handling in infancy upon behavior and adrenocortical activity: Suggestions for a neuroendocrine mechanism. In The development of self-regulatory mechanisms (ed. D.W. Walcher and D.L. Peters), pp. 39-64. Academic Press, New York.

Denenberg, V.H., J.M. Woodcock, and K.M. Rosenberg. 1968. Long-term effects of preweaning and postweaning free-environment experience on rats problem-solving behavior. J. Comp. Physiol. Psychol. 66: 533-535.

Diamond, M.C. 1988. Enriching heredity. Free Press, New York.

Driscoll, P. and K. Bättig. 1982. Behavioral, emotional and neurochemical profiles of rats selected for extreme differences in active, two-way active performance. In Cenetics of the brain (ed. I. Lieblich), pp. 95-123. Elsevier Biomedical Press, Amsterdam, The Netherlands.

Escorihuela, R.M., A. Tobeña, and A. Fernández-Teruel. 1994. Environmental enrichment reverses the detrimental action of early inconsistent stimulation and increases the beneficial effects of postnatal handling on shuttlebox learning in adult rats. Behav. Brain Res. 61: 169-173.

Escorihuela, R.M., A. Tobeña, P. Driscoll, and A. Fernández-Teruel. 1995. Effects of training, early handling and perinatal flumazenil on shuttle box acquisition in Roman low-avoidance rats: Toward overcoming a genetic deficit. Neurosci. Biobehav. Rev. (in press).

Fernández-Teruel, A., R.M. Escorihuela, P. Driscoll, A. Tobeña, and K. Bättig. 1991. Infantile (handling) stimulation and behavior in young Roman high- and low-avoidance rats. Physiol. Behav. 50: 563-565.

Fernández-Teruel, A., R.M. Escorihuela, J.F. Núñez, M. Gomà, P. Driscoll, and A. Tobeña. 1992. Early stimulation effects on novelty-induced behavior in two psychogenetically-selected rat lines with divergent emotionality profiles. Neurosci. Lett. 137: 185-188.

Fernández-Teruel, A., P. Driscoll, R.M. Escorihuela, A. Tobeña, and K. Bättig. 1993. Postnatal handling, perinatal flumazenil, and adult behavior of the Roman rat lines. Pharmacol. Biochem. Behav. 44: 783-789. 
Ferré, P., J.F. Núñez, E. García, A. Tobeña, R.M Escorihuela, and A. Fernández-Teruel. 1995. Postnatal handling reduces anxiety as measured by "emotional rating" and hyponeophagia tests in female rats. Pharmacol. Biochem. Behav. (in press).

Gentsch, C., M. Lichtsteiner, P. Driscoll, and H. Feer. 1982. Differential hormonal and physiological responses to stress in Roman high- and low- avoidance rats. Physiol. Behav. 28: 259-263.

Greenough, W.T., G.S. Whiters, and C.S. Wallace. 1990. Morphological changes in the nervous system arising from behavioral experience: what is the evidence that they are involved in learning and memory? In The Biology of memory, Symposia Medica Hoechst 23 (ed. L.R. Squire and E. Lindenlaub), pp. 159-185. Schattauder Verlag, Stuttgart/New York.

Issa, A.M., W. Rowe, S. Gauthier, and M.J. Meaney. 1990. Hypothalamic-pituitary-adrenal activity in aged, cognitively impaired and cognitively unimpaired rats. J. Neurosci. 10: $3247-3254$.

Levine, S., G.C. Haltmeyer, G.G. Karas, and V.H. Denenberg. 1967. Physiological and behavioral effects of infantile stimulation. Physiol. Behav. 2: 55-59.

Liljequist, R., B.G. Henriksson, N. Latif, T. Pham, B. Winblad, and A.H. Mohammed. 1993. Subchronic MK-801 treatment to juvenile rats attenuates environmental effects on adult spatial learning. Behav. Brain Res. 56: 107-114.

Lipp, H.-P., H. Schwegler, W.E. Crusio, D.P. Wolfer, M.-C. Leisinger-Trigona, B. Heimrich, and P. Driscoll. 1989. Using genetically-defined rodent strains for the identification of hippocampal traits relevant for two-way avoidance behavior: A non-invasive approach. Experientia 45: 845-859.

Meaney, M.J., D.H. Aitken, C. Van Berkel, S. Bhatnagar, and R.M. Sapolsky. 1988. Effect of neonatal handling on age-related impairments associated with the hippocampus. Science 239: 766-768.

Meaney M.J., D.H. Aitken, S. Sharma, V. Viau, and A. Sarrieau. 1989. Postnatal handling increases hippocampal type II, glucocorticoid receptors and enhances adrenocortical negative feed-back efficacy in the rat. Neuroendocrinology 50: $597-604$.

Nil, R. and K. Bättig. 1981. Spontaneous maze ambulation and Hebb-Williams learning in Roman high-avoidance and Roman low-avoidance rats. Behav. Neural Biol.

33: $465-475$

Núñez, J.F., P. Ferré, E. García, R.M. Escorihuela, A. Fernández-Teruel, and A. Tobeña. 1995. Postnatal handling reduces emotionality ratings and accelerates two-way active avoidance in female rats. Physiol. Behav. (in press).

Olsson, T., A.H. Mohammed, L.F. Donaldson, B.G. Henriksson, and J.R. Seckl. 1994. Glucocorticoid receptor and NGFI-A gene expression are induced in the hippocampus after environmental enrichment in adult rats. Mol. Brain Res. 23: 349-353.

Paylor, R., S.K. Morrison, J.W. Rudy, L.T. Waltrip, and J.M Wehner. 1992. Brief exposure to an enriched environment improves performance on the Morris water task and increases hippocampal cytosolic protein kinase $C$ activity in young rats. Behav. Brain Res. 52: 49-59.

Renner, M.J. and M.R. Rosenzweig. 1987. Enriched and impoverished environments. Springer-Verlag, New York.

Sapolsky, R.M. 1992. Stress, the aging brain, and the mechanisms of neuron death. The MIT Press, London, UK.

Schöpke, R., D.P. Wolfer, H.-P. Lipp, and M.-C. Leisinger-Trigona. 1991. Swimming navigation and structural variations of the infrapyramidal mossy fibers in the hippocampus of the mouse. Hippocampus 1: 315-328.

Van Gool, W.A., M. Mirmiran, and F. Van Haaren. 1985. Spatial memory and visual evocked potentials in young and old rats after housing in an enriched environment. Behav. Neural Biol. 44: 454-469.

Venable, N., T. Pinto-Hamuy, J.A. Arraztoa, M.T. Contador, A. Chellew, C. Perán, and X. Valenzuela. 1988. Greater efficacy of preweaning than postweaning environmental enrichment on maze learning in adult rats. Behav. Brain Res 31: 89-92.

Walker, C.D., R.W. Rivest, M.J. Meaney, and M.L. Aubert. 1989. Differential activation of the pituitary-adrenocortical axis after stress in the rat: Use of two genetically selected lines (Roman low- and high-avoidance rats) as a model. J. Endocrinol. 123: 477-485.

Willig, F., M. M'Harzi, C. Bardelay, D. Viet, and J. Delacour. 1991. Roman strains as a psychogenetic model for the study of working memory: Behavioral and biochemical data. Pharmacol. Biochem. Behav. 40: 7-16.

Willig, F., D. Van de Velde, J. Laurent, M. M'Harzi, and J. Delacour. 1992. The Roman strains of rats as a psychogenetic tool for pharmacological investigation of working memory: example with RU 41656. Psychopharmacology 107: 415-424.

Yau, J.L., R.G. Morris, and J.R. Seckl. 1994. Hippocampal corticosteroid receptor mRNA expression and spatial learning in the aged Wistar rat. Brain Res. 657: 59-64.

Zeier, H., K. Bättig, and P. Driscoll. 1978. Acquisition of DRL-20 behavior in male and female Roman high- and low-avoidance rats. Physiol. Behav. 20: 791-793.

Received December 2, 1994; accepted in revised form March 21, 1995. 

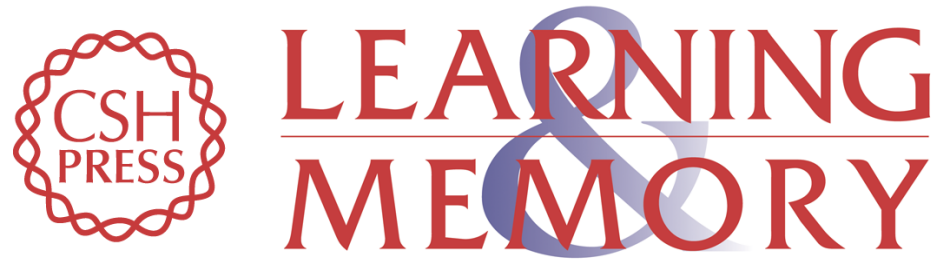

\section{Environmental enrichment and postnatal handling prevent spatial learning deficits in aged hypoemotional (Roman high-avoidance) and hyperemotional (Roman low-avoidance) rats.}

R M Escorihuela, A Tobeña and A Fernández-Teruel

Learn. Mem. 1995, 2:

Access the most recent version at doi:10.1101//m.2.1.40

References This article cites 27 articles, 3 of which can be accessed free at: http://learnmem.cshlp.org/content/2/1/40.full.html\#ref-list-1

License

Email Alerting

Receive free email alerts when new articles cite this article - sign up in the box at the Service top right corner of the article or click here. 